\title{
Automatic Simulation of Moving Products Using Line Follower and Conveyor
}

\author{
Almadora Anwar Sani ${ }^{1, *}$ Rachmat Dwi $\mathrm{S}^{1}$ Irawan Malik $^{1}$ Ali Medi ${ }^{1}$ Agus Nugraha ${ }^{1}$ \\ ${ }^{I}$ Mechanical engineering, Politeknik Negeri Sriwijaya \\ "Corresponding author. Email: almadora@polsri.ac.id
}

\begin{abstract}
The manufacturing industry is an industrial technology that uses machinery, equipment and labor in the processing of raw materials into new products that can be used and have a sale value. The manufacturing industry is closely related to engineering or engineering. In the manufacturing industry there is an automation system. Automation system by moving goods from point $\mathrm{A}$ to point $\mathrm{B}$ or to point $\mathrm{C}$ and so on. So that goods can move can use the conveyor belt as an intermediary. The moving tool is designed to work automatically; the moving tool uses the Arduino as a motion controller. This tool is in the form of miniature and simulation. Testing tools by controlling the movement of goods from point $\mathrm{A}$ to point $\mathrm{B}$ and to point $\mathrm{C}$ works well, the timing of moving goods, and the speed of the conveyor.
\end{abstract}

Keywords: Automatic, Microcontroller, Conveyors

\section{INTRODUCTION}

The manufacturing industry is an industrial technology that uses machinery, equipment and labor in the processing of raw materials into new products that can be used and have a sale value. The manufacturing industry is closely related to engineering. In the manufacturing industry there is an automation system.

Automation systems work with machines in the production process, the use of automation systems makes it very easy to implement industrial automation. Computer technology is used to design and operate machines that work automatically. The development of the industrial revolution 4.0 resulted in a "smart factory". In a modular structured smart factory, cyberphysical systems monitor physical processes, create virtual physical copies, and make decentralized decisions. Through the Internet, cyber-physical systems communicate and cooperate with each other and humans simultaneously.

The resulting products will then be transferred, to move the products using a conveyor running. The resulting product from point $\mathrm{A}$ can be moved to point $\mathrm{B}$ or to point $\mathrm{C}$ and so on automatically. The advantages of using a conveyor:

- $\quad$ Can do the job quickly

- Can reduce production costs
- Reducing Air Pollution

- Can move items by many

- Reducing the number of work accidents

\section{STUDY LITERATURE}

The development of mechatronic components in the end was able to produce a system that could replace the functions of tens or even hundreds of relays with just one programmable microcontroller chip.

In its application, automation is used to reduce manufacturing process times, errors due to operators and storage. One part of the production process is the packaging process, which is a series of processes so that the product is stored in a package [1].

A conveyor belt comprising at least one belt edge arranged on a longitudinal side of the conveyor belt is characterised in that threads of a tear-proof material are arranged in the belt edge. The threads are preferably embodied as fabric and arranged as a fabric inlay in the belt edge. A higher strength is thereby achieved [2].

A conveyor comprises a base conveyor section, at least one moveable conveyor section selectively position able relative to the base conveyor section, a conveyor member arranged to provide a conveying surface on said conveyor sections, a drive system to drive the movable conveyor section and/or the 
conveyor member, and a contact sensor connected to a control device for interrupting the movement of the conveyor member and/or the movable conveyor section in response to a signal generated by the contact sensor, wherein said contact sensor comprises an actuation element adapted to transfer both vertical and horizontal contact forces to said contact sensor [3].

The microcontroller itself is a chip or IC (integrated circuit) that can be programmed using a computer. The purpose of embedding the program on the microcontroller is so that the electronic circuit can read the input, process the input and then produce the desired output. So the microcontroller serves as the "brain" which controls the input, process and output of an electronic circuit [4].

The results of the research conducted can be concluded that, the design of the automation system for the chamfering stopper valve process on the Bench Lathe SD-32A machine at PT Dharma Precision Parts has been completed and the new processing time for the chamfering process is about 5 seconds / part. By using an automation system in the stopper valve part production process, it is expected to increase production capacity and reduce the use of labor so that it can have a positive impact on the company [5].

Disclosed is a conveyor belt which is provided with a Plurality of rollers, a detection portion for detecting the state of rollers, and processing portion connected to the detection portion and processes output signals from the detection portion. The conveyor belt has a mount portion on which the processing portion is mounted. The mount portion is provided at the end part of the conveyor belt in the width direction thereof. Providing a detection portion for processing output signals from a sensor for detecting rotational failure at the end of the conveyor belt in the width direction thereof makes it possible to suppress increased costs in a belt conveyor apparatus and to reduce the frequency of failure of the detection portion [6].

The definition of a conveyor belt can be interpreted as a series of conveyor belts that are used to move or transport goods or materials horizontally or at an angle. The belt material used on the conveyor belt can be made of rubber or metal depending on the type of goods being moved. During its development, there are conveyor belts that are used to move goods or materials vertically, such as in a scraper conveyor. Meanwhile, the materials that can be transported using a conveyor belt are quite diverse, including sand, cement, coal, quartz, granite, food packaging, beverage bottles and other goods [7].

\section{RESEARCH METHODS}

In this research, the methods to be used include observation, literature study, designing products with CAD, processing programs, product simulations and application to work pieces. The sequence of the research can be explained in the flowchart in figure 1. This study uses an experimental method. The design results are made with a laser cutting machine and a $3 \mathrm{~d}$ printing machine, then the printed parts are assembled into a miniature manufacturing machine.

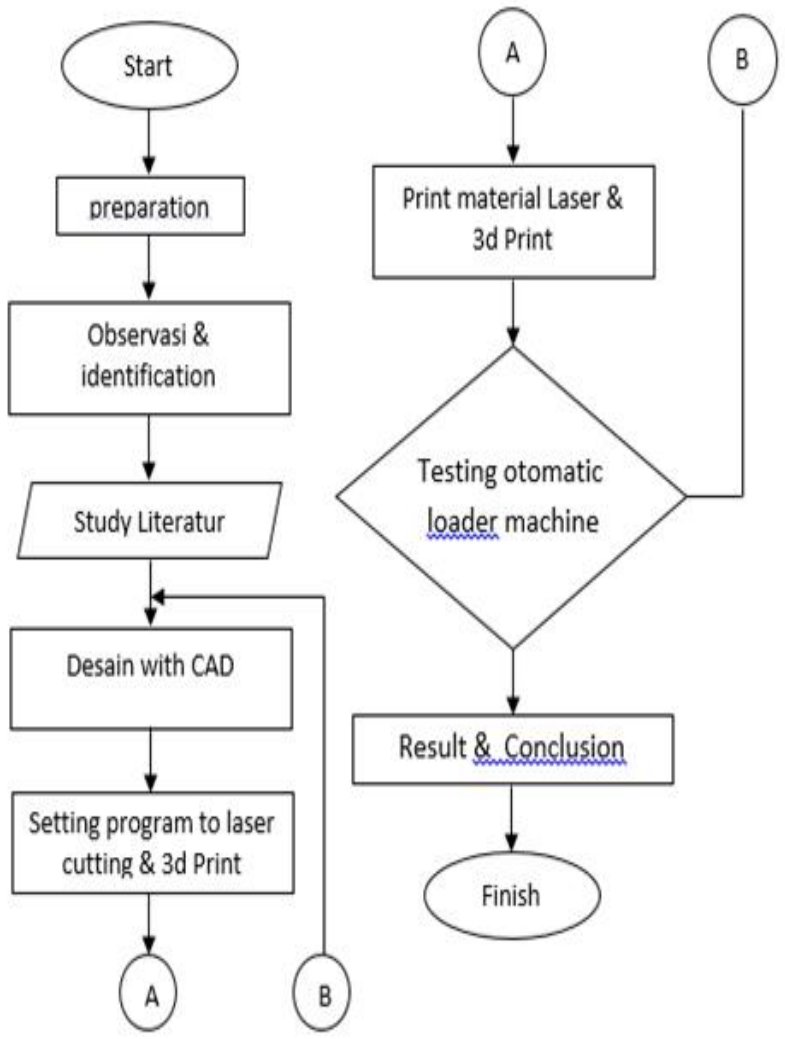

Figure 1 Flowchart.

The steps taken in the research method can be explained as follows:

- Starting with preparation, group discussions discuss areas to be worked on according to group members' field competencies.

- Doing observations, looking for background problems, and formulating problems that will be studied further.

- Looking for references on scientific journals, patents, books for literature study.

- Designing and making designs using CAD

- The design results are set and the program converted using a laser cutting machine and 3D printing to make miniature parts for moving goods. 
- Print the design using a laser cutting machine and $3 \mathrm{~d}$ printing.

- Assembly parts and performance testing of moving tools.

- Analyse the results of the transporter performance, if the results of the analysis are good, continue to the conclusion. If the results are not good, go back to the design, improve and refine the design and so on.

- Research is complete, if the results are in accordance with the problem formulation and the tools can function properly.

\section{RESULT AND ANALYST}

The moving machine uses the Line Follower Robot, following the line. The work process of the tool, namely the production / goods carried by the conveyor, is then given to the line follower robot. Then automatically from conveyor A to conveyor B to continue the process of moving goods. After moving the goods on conveyor $\mathrm{B}$, the line follower robot moves back to conveyor A to collect the production results. The scheme of moving goods can be seen in Figure 2.

The line follower robot uses an infrared sensor with a motor as a driving force.

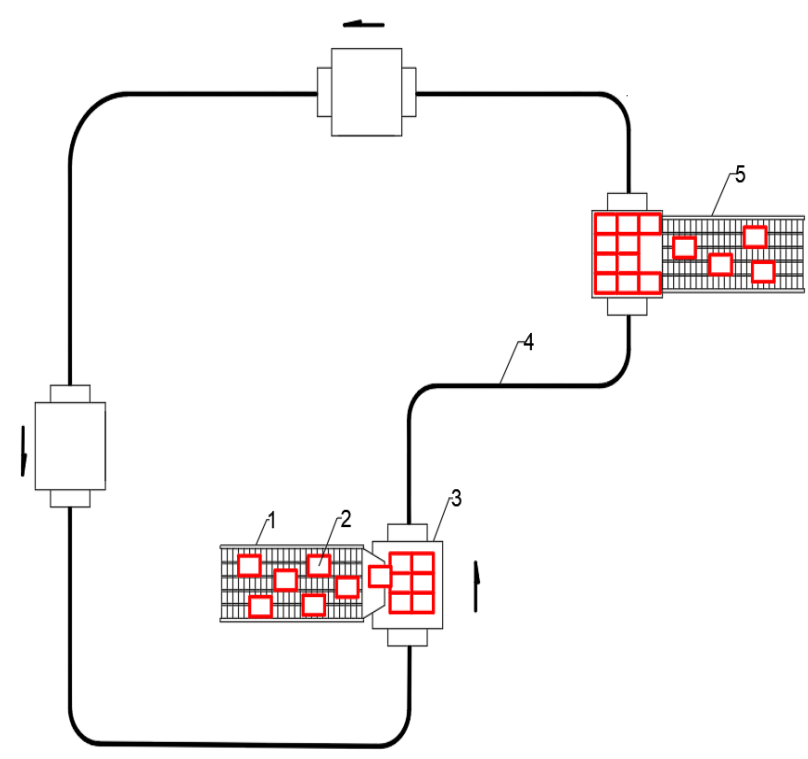

Figure 2 Schematic automation moving product.

Explanation:
1. Conveyor A
2. Object
3. Line Follower
4. Line
5. Conveyor B

Table 1 Performance Test

\begin{tabular}{|c|c|c|c|c|c|}
\hline & test 1 & test 2 & test3 & test4 & test5 \\
\hline 1 & 1 & 1 & 0 & 1 & 1 \\
\hline 2 & 1 & 1 & 0 & 1 & 1 \\
\hline 3 & 0 & 1 & 1 & 1 & 1 \\
\hline 4 & 1 & 1 & 1 & 1 & 1 \\
\hline 5 & 1 & 0 & 1 & 0 & 0 \\
\hline 6 & 0 & 1 & 0 & 1 & 1 \\
\hline 7 & 1 & 1 & 1 & 1 & 1 \\
\hline 8 & 0 & 1 & 1 & 0 & 1 \\
\hline 9 & 1 & 1 & 1 & 1 & 0 \\
\hline 10 & 1 & 1 & 0 & 1 & 1 \\
\hline 11 & 0 & 1 & 1 & 1 & 1 \\
\hline 12 & 1 & 0 & 1 & 1 & 1 \\
\hline 13 & 1 & 1 & 1 & 0 & 1 \\
\hline 14 & 0 & 0 & 0 & 1 & 0 \\
\hline 15 & 1 & 1 & 1 & 0 & 1 \\
\hline 16 & 1 & 0 & 1 & 1 & 0 \\
\hline 17 & 1 & 0 & 0 & 1 & 1 \\
\hline 18 & 1 & 1 & 1 & 1 & 1 \\
\hline 19 & 1 & 1 & 1 & 0 & 1 \\
\hline 20 & 1 & 0 & 1 & 1 & 0 \\
\hline Total & $\mathbf{1 5}$ & $\mathbf{1 4}$ & $\mathbf{1 4}$ & $\mathbf{1 5}$ & $\mathbf{1 5}$ \\
\hline Percentase & $\mathbf{7 5 \%}$ & $\mathbf{7 0} \%$ & $\mathbf{7 0} \%$ & $\mathbf{7 5 \%}$ & $\mathbf{7 5 \%}$ \\
\hline & & & & &
\end{tabular}

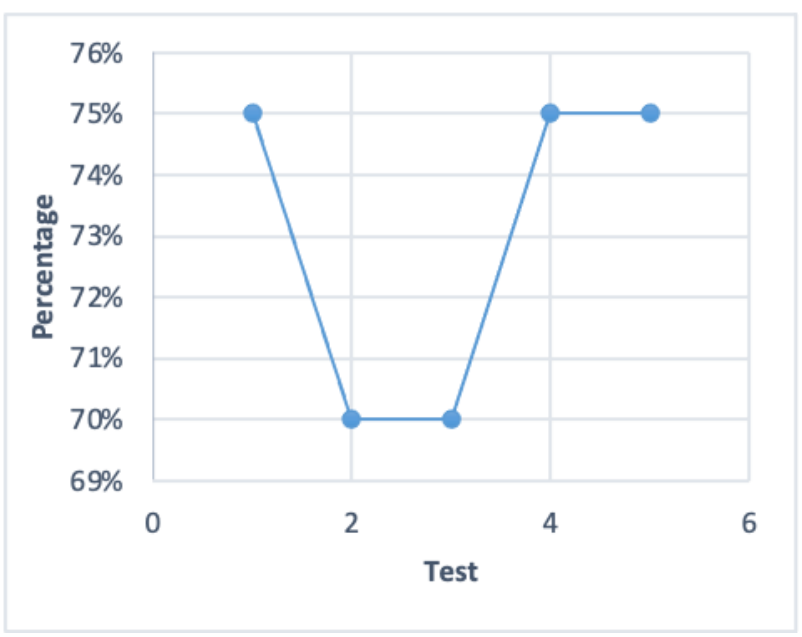

Figure 3 Chart Test Performance

Test 1 out of 20 times, the results were 15 times successful and 5 times failed. Test 2 of 20 times the results obtained 14 times successful and 6 times failed. Test 3 out of 20 times the results were obtained 14 times successful and 6 times failed. Test 4 out of 20 times the results were 15 times successful and 5 times failed. Test 5 out of 20 times the results were 15 times successful and 5 times failed. On average, $73 \%$ of the performance was successful. 
Anova: Single Factor

\begin{tabular}{lrrrl} 
SUMMARY & \multicolumn{1}{c}{ Count } & \multicolumn{1}{c}{ Sum } & Average & Variance \\
\hline Groups & 20 & 15 & 0.75 & 0.197368 \\
Column 1 & 20 & 14 & 0.7 & 0.221053 \\
Column 2 & 20 & 14 & 0.7 & 0.221053 \\
Column 3 & 20 & 15 & 0.75 & 0.197368 \\
Column 4 & 20 & 15 & 0.75 & 0.197368 \\
Column 5 & & & &
\end{tabular}

\begin{tabular}{|c|c|c|c|c|c|c|}
\hline Source of Variation & SS & $d f$ & MS & $F$ & $P$-value & F crit \\
\hline Between Groups & 0.06 & 4 & 0.015 & 0.072519 & 0.990283 & 2.467494 \\
\hline Within Groups & 19.65 & 95 & 0.206842 & & & \\
\hline Total & 19.71 & 99 & & & & \\
\hline
\end{tabular}

The results of the conveyor performance test were analysed using the Anova single factor test. ANOVA Single factor test results show $\mathrm{F}$ table $<\mathrm{F}$ count. Then $\mathrm{H} 0$ is accepted, from tests 1 to 5 , each test is carried out 20 times the experiment results are obtained. The performance of the conveyor works well. So, the results of the conveyor performance test of this study, there is no difference in the ability of 5 tests and 20 trials.

\section{CONCLUSION}

This simulation of moving goods is in the form of a prototype and can be developed for further research. The process of moving goods can be done automatically, research conclusions:

- The process of moving goods can work automatically

- The process of moving goods makes human work easier
- The process of moving goods can work well

- The process of moving goods can still be developed and perfected

\section{REFERENCES}

[1] D.L. Zariatin, E. H. O. Tambunan, A. Suwandi, 2016, "Design and build a product packaging system simulator based on programmable logic control", Jurnal Sintek, Vol 10, No. 2, 2016, ISSN 2088-9038.

[2] Detlef Water, "Conveyor Belt", United States, Patent Application Publication, US 2009/0014289 A1, Jan. 15, 2009.

13] Erik. S. Petersen, 2006, "Conveyor", United States, Patent Application Publication, US 2006/0011455 A1, Jan. 19, 2006.

[4] Ilham effendi, 2018. "Understanding and Strengths of Arduino". https://www.it-jurnal.com/pengertiandan-kelebihan-arduino/

[5] M. I. Fauzan, H. Rachmat, R. A. Anugrah, 2016, "Designing Automation System Chamfer Part Stopper Valve on Bench Lathe Sd-32a Machine at Pt Dharma Precision Parts", Jurnal Rekayasa Sistem \& Industri, Vol 3, No. 1, Januari 2016,

[6] Toshiki Sakaguchi, 2012, "Conveyor Belt". United States, Patent Application Publication, US 2012/0012443 A1, Jan. 19, 2012.

[7] www.dnm.co.id 